\title{
Mutation screening of NOS1AP gene in a large sample of psychiatric patients and controls
}

\author{
Richard Delorme ${ }^{1,2,3^{*}}$, Catalina Betancur ${ }^{8,9}$, Isabelle Scheid ${ }^{1}$, Henrik Anckarsäter ${ }^{4}$, Pauline Chaste ${ }^{1,2,3}$, \\ Stéphane Jamain ${ }^{2}$, Franck Schuroff ${ }^{2,5}$, Gudrun Nygren ${ }^{4}$, Evelyn Herbrecht ${ }^{2}$, Anne Dumaine ${ }^{2}$, \\ Marie Christine Mouren ${ }^{3}$, Maria Råstam ${ }^{4}$, Marion Leboyer ${ }^{2,5}$, Christopher Gillberg ${ }^{4,6}$, Thomas Bourgeron ${ }^{1,7}$
}

\begin{abstract}
Background: The gene encoding carboxyl-terminal PDZ ligand of neuronal nitric oxide synthase (NOSTAP) is located on chromosome 1q23.3, a candidate region for schizophrenia, autism spectrum disorders (ASD) and obsessive-compulsive disorder (OCD). Previous genetic and functional studies explored the role of NOSIAP in these psychiatric conditions, but only a limited number explored the sequence variability of NOS1AP.

Methods: We analyzed the coding sequence of NOS1AP in a large population $(n=280)$, including patients with schizophrenia ( $n=72)$, ASD ( $n=81)$ or OCD $(n=34)$, and in healthy volunteers controlled for the absence of personal or familial history of psychiatric disorders $(n=93)$.

Results: Two non-synonymous variations, V37I and D423N were identified in two families, one with two siblings with OCD and the other with two brothers with ASD. These rare variations apparently segregate with the presence of psychiatric conditions.

Conclusions: Coding variations of NOSIAP are relatively rare in patients and controls. Nevertheless, we report the first non-synonymous variations within the human NOS1AP gene that warrant further genetic and functional investigations to ascertain their roles in the susceptibility to psychiatric disorders.
\end{abstract}

\section{Background}

The current concepts adopted by DSM-IV and ICD-10 that define a psychiatric disorder as a single entity may be misleading and hamper the identification of susceptibility genes. Some disorders classically considered as separate conditions could be envisaged as being the phenotypic extremes of a continuum caused by an overlapping set of genes. Indeed, the same region on chromosome 1q23.3 was detected in whole genome scans for separate psychiatric disorders and could therefore contain one shared susceptibility gene for these conditions. For schizophrenia, several linkage studies detected a significant linkage at 1q23.3 [1-6]. The same region was detected in two linkage studies in autism spectrum disorders (ASD). Buxbaum et al., [7] reported an association between patients with autism and obsessive-compulsive behaviors $(\mathrm{OCD})$, and D1S1677 ( $\mathrm{p}$ value $=0.003$ under multipoint nonparametric analyses). These results were

\footnotetext{
* Correspondence: richard.delorme@rdb.aphp.fr

${ }^{1}$ Human Genetics and Cognitive Functions, Institut Pasteur, Paris, France
}

replicated by Ylisaukko-oja et al., [8] who found a significant linkage between patients with Asperger syndrome, known to have frequent OC symptoms [9], and 1q23.3 (D1S484, LOD score $=3.58$ under dominant model). In OCD patients a linkage at chromosome 1q23.3 was observed in the early-onset group (age at onset $<18$ years) [10]. Non parametric multipoint linkage analysis produced a maximum LOD score of 2.94 at D1S1679 with an empirical $\mathrm{p}$ value equal at 0.001 after permutations.

Several genes located in region 1q23.3 have been studied, e.g. the regulator of G-protein signalling 4 gene [11-14], the myelin protein zero like 1 gene [15], the $U H M K 1$ gene [16], encoding for a serine/threonine protein kinase, and the carboxyl-terminal PDZ ligand of neural nitric synthase (NOS1AP) gene. Among these genes, NOS1AP remains the most promising candidate. Brzustowicz et al., [17] analyzed 14 microsatellites and 15 single nucleotide polymorphisms (SNPs) between D1S1653 and D1S1679, and found a significant 
association between NOS1AP and SCZ. These results were reproduced in three independent samples of patients [18-20]. NOS1AP is in adaptor protein, which binds to neuronal nitric oxyde synthase, eliciting Snitrosylation and activation of Dextras 1, which regulate NMDA receptor-mediated glutamate neurotransmission [21]. Using quantitative real time polymerase chain reaction, $\mathrm{Xu}$ et al., [22] reported an increased of the NOS1AP short isoform mRNA in the dorso-prefrontal cortex of schizophrenic patients. The over expression this short isoform mRNA could disrupt NMDA receptor function [23] and increase the risk of a psychiatric condition such as SCZ, ASD or OCD. More recently, Wratten et al., [24] reported that a risk allele, located in intron 2 and associated with schizophrenia, could enhance transcription factor binding and increase gene expression. Together, these findings make NOS1AP as a compelling candidate for several psychiatric disorders. However, no coding mutation in NOS1AP has been reported [17] and the positive association only concerns SNPs that have no established functional role. The aim of this study was to explore the expression pattern of NOS1AP in human tissues and its sequence variability in a large population of subjects $(n=280)$, including patients with schizophrenia $(\mathrm{n}=72)$, ASD $(\mathrm{n}=81)$ or OCD $(n=34)$, and in healthy volunteers controlled for the absence of personal or familial history of psychiatric disorders $(\mathrm{n}=93)$.

\section{Methods \\ Patients}

Schizophrenic (46 males, 26 females) and OCD (21 males, 13 females), fulfilling the DSM-IV criteria for their disorders, were recruited in Paris (Department of Adult Psychiatry, H. Mondor and A. Chenevier Hospitals, Créteil, and Department of Child and Adolescent Psychiatry, R Debré Hospital, France). Lifetime psychiatric evaluation was carried out during a direct interview by trained psychiatrists using the Diagnostic Interview for Genetic Studies (DIGS) [25] and the Kiddie-Schedule of Affective Disorders and Schizophrenia - epidemiologic version [26] for OCD probands aged under 18 years. Probands with ASD (72 males, 9 females; 46 trios, 35 multiplex families) were recruited by the Paris Autism Research International Sib-pair (PARIS) study. Patients with autism or Asperger's syndrome fulfilled the DSMIV criteria for autistic disorder and the Autism Diagnostic Interview Revised algorithm for ICD-10 childhood autism and the Autism Diagnostic Interview-Revised [27] criteria for childhood autism. Subjects were included only after a thorough clinical and medical work-up comprising a full medical and family history, physical and neuropsychological examination, standard karyotyping and fragile- $\mathrm{X}$ testing, blood and urine analyses for metabolic screening. Healthy controls of European descent $(n=93)$ were recruited among blood donors at the Pitié-Salpétrière Hospital in Paris, France (49 males, 44 females). All controls were included after being interviewed with the DIGS and with the Family Interview for Genetic Studies [28] to confirm the absence of both personal and familial history of psychiatric disorders.

The local Research Ethics Boards reviewed and approved the study. Written informed consent was obtained from all probands and controls. If the proband was under 18 years old, the proband's consent and written parental consent were obtained.

\section{Gene characterization}

The genomic structure of NOS1AP was obtained from http://genome.ucsc.edu/. Exon-intron boundaries were identified and primers designed to cover the regulatory splice site regions and the exons using the previous Web site. NOS1AP covers a genomic region of $298 \mathrm{~Kb}$ and comprises 10 exons. As reported by Xu et al., [19], the long isoform is composed of exons 1 to 10 and encodes a protein of $75 \mathrm{kDa}$. The short isoform is composed of exons 9 and 10, and encodes a protein of $30 \mathrm{kDa}$. Both proteins contain a PDZ domain.

\section{Expression of NOS1AP long and short isoforms in human tissues}

One microgram of total RNA from different tissues and specifically from regions of the human brain was reverse transcribed using the Gene Amp RNA PCR kit (PerkinElmer Corp., Norwalk, CT) and primers located in exons 1-7, 6-9 and 8-10 (forward -reverse) for the long isoform and in the 3'UTR-exon10 for the short isoform [22]. The ages of the two males and the two females studied were $74,42,55$, and 36 years-old, with a postmortem delay of $10,21,24$, and $2 \mathrm{~h}$, respectively. Normal control human brains were obtained at autopsy under guidelines approved by the ethics committee

\section{Mutation screening in psychiatric patients}

The mutation screening was conducted in two steps. First, the exonic sequences of NOS1AP were screened for genetic variants by direct sequencing with the BigDye kit v3.0 (Applied Biosystems) according to the manufacturer's instructions in a sample of schizophrenic patients $(n=72)$, ASD patients $(n=81)$ and healthy volunteers $(\mathrm{n}=93)$. The exonic sequence and the adjacent intronic sequences were considered first as most likely to harbour functionally important variants. Primers were designed using Amplify V3.1 software http:// engels.genetics.wisc.edu/amplify/ and are available on request. Then, the rare variants identified were screened by direct sequencing in a additionnal sample containing 
224 patients with ASD and 225 patients with schizophrenia. Patients included in this second step fulfilled the same criteria as patients enrolled in the first steps of the study and described previously.

\section{Association study in schizophrenic and ASD patients}

The association study was conduct using 11 SNPs with a minor allele frequency higher than 0.05 and identified by direct sequencing in the schizophrenic and ASD patients (table 1). The program HaploView (v3.32) was used to test for concordance with Hardy-Weinberg equilibrium (HWE), calculate D' between SNP pairs and identify linkage disequilibrium (LD) blocks, which were defined with confidence intervals [29]. The $P$ values for each marker and haplotype were adjusted from permutation test with 10,000 simulations if significance was under 0.01. Comparison of genotype frequencies between cases and controls was performed with

Table 1 Allele and genotype frequencies of frequent polymorphisms in NOS1AP*

\begin{tabular}{|c|c|c|c|c|c|c|c|c|}
\hline \multirow[t]{2}{*}{ 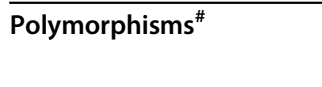 } & \multirow[t]{2}{*}{ Location } & \multicolumn{3}{|c|}{ Number of alleles (frequency) } & \multicolumn{4}{|c|}{ Number of Genotype (frequency) } \\
\hline & & Allele 1 & Allele 2 & $P(\mathrm{df}=1)$ & 11 & 12 & 22 & $P(\mathrm{df}=2)$ \\
\hline rs10918776 & Intron 2 & G & $\mathrm{C}$ & & & & & \\
\hline SCZ & & $100(0.77)$ & $32(0.23)$ & 0.46 & 42 & 22 & 5 & $0.57^{\S}$ \\
\hline ASD & & $117(0.72)$ & $45(0.28)$ & 0.06 & 39 & 37 & 4 & $0.06^{\S}$ \\
\hline Controls & & $142(0.80)$ & $34(0.20)$ & & 57 & 28 & 3 & \\
\hline rs10800405 & Intron 3 & $\mathrm{C}$ & G & & & & & \\
\hline SCZ & & $91(0.76)$ & $31(024)$ & 0.92 & 37 & 25 & 3 & $0.98^{\S}$ \\
\hline ASD & & $102(0.74)$ & $36(0.26)$ & 0.63 & 34 & 33 & 1 & $0.60^{\S}$ \\
\hline Controls & & $113(0.77)$ & $35(0.23)$ & & 43 & 29 & 3 & \\
\hline rs347306 and rs347307 & Intron 5 & $\mathrm{C}$ and $\mathrm{T}$ & $T$ and $C$ & & & & & \\
\hline $\mathrm{SCZ}$ & & $74(0.56)$ & $60(0.44)$ & 0.19 & 20 & 38 & 12 & 0.23 \\
\hline ASD & & $82(0.52)$ & $76(0.48)$ & 0.98 & 17 & 41 & 20 & 0.46 \\
\hline Controls & & $87(0.52)$ & $81(0.48)$ & & 15 & 54 & 18 & \\
\hline rs3751285 & Intron 6 & A & G & & & & & \\
\hline SCZ & & $68(0.77)$ & $20(0.33)$ & 0.35 & 28 & 12 & 4 & $0.32^{\S}$ \\
\hline ASD & & $97(0.71)$ & $39(0.29)$ & 0.96 & 34 & 27 & 6 & 0.97 \\
\hline Controls & & $106(0.72)$ & $42(0.28)$ & & 39 & 31 & 6 & \\
\hline rs3751284 & Exon 6 & $\mathrm{C}$ & $\mathbf{T}$ & & & & & \\
\hline SCZ & & $58(0.66)$ & $30(0.34)$ & 0.35 & 20 & 18 & 6 & 0.45 \\
\hline ASD & & $75(0.55)$ & $61(0.45)$ & 0.32 & 20 & 34 & 13 & 0.69 \\
\hline Controls & & $88(0.60)$ & $60(0.40)$ & & 26 & 39 & 11 & \\
\hline rs905721 & Intron 8 & $\mathrm{C}$ & $\mathbf{T}$ & & & & & \\
\hline SCZ & & $96(0.70)$ & $42(0.30)$ & 0.10 & 33 & 30 & 6 & 0.22 \\
\hline All SCZ & & $353(0.62)$ & $213(0.38)$ & 0.92 & 114 & 125 & 44 & 0.86 \\
\hline ASD & & $104(0.66)$ & $54(0.34)$ & 0.33 & 31 & 41 & 6 & 0.02 \\
\hline All ASD & & $360(0.64)$ & $198(0.36)$ & 0.41 & 115 & 130 & 34 & 0.27 \\
\hline Controls & & $98(0.65)$ & $52(0.35)$ & & 37 & 24 & 14 & \\
\hline All controls & & $309(0.62)$ & $189(0.38)$ & & 102 & 105 & 42 & \\
\hline rs348624 and rs1964052 & Exon 9 and intron 9 & $C$ and $C$ & $\mathrm{~T}$ and $\mathrm{T}$ & & & & & \\
\hline $\mathrm{SCZ}$ & & $121(0.89)$ & $15(0.11)$ & 0.48 & 54 & 13 & 1 & $0.49^{\S}$ \\
\hline All SCZ & & $500(0.87)$ & $74(0.13)$ & 0.34 & 218 & 63 & 6 & 0.50 \\
\hline ASD & & $132(0.85)$ & $24(0.15)$ & 0.07 & 55 & 18 & 3 & $0.07^{\S}$ \\
\hline All ASD & & $472(0.86)$ & $74(0.14)$ & 0.22 & 206 & 60 & 7 & 0.39 \\
\hline Controls & & $137(0.91)$ & $13(0.09)$ & & 62 & 13 & 0 & \\
\hline All controls & & $283(0.89)$ & $34(0.11)$ & & 128 & 29 & 2 & \\
\hline rs164146 and rs164147 & Exon 10 & $G$ and $C$ & $C$ and $A$ & & & & & \\
\hline SCZ & & $104(0.83)$ & $22(0.17)$ & 0.71 & 43 & 18 & 2 & $0.73^{\S}$ \\
\hline ASD & & $133(0.84)$ & $25(0.16)$ & 0.99 & 56 & 20 & 2 & $0.91^{\S}$ \\
\hline Controls & & $128(0.84)$ & $24(0.16)$ & & 57 & 23 & 1 & \\
\hline
\end{tabular}

*Polymorphisms included have a minor allele frequency above $0.05 .{ }^{*}$ Markers are listed from centromere au telomere. ${ }^{\S}$ Fischer exact Test. Significant $P$ values $(<0.05)$ are in bold. Abbreviations: ASD: autism spectrum disorders, SCZ: schizophrenia. 
chi-square test. The association study was conducted in two steps: first, all the schizophrenic patients $(n=72)$ and all the ASD patients $(n=81)$ were compared to the healthy volunteers $(n=93)$ to detect a potential association. Second, we included additional schizophrenic patients $(\mathrm{n}=224)$, ASD patients $(\mathrm{n}=225)$ and controls $(\mathrm{n}=193)$ to increase the power of detecting an association with the SNP rs348624 (R334R) located in exon 9. This SNP was previously reported to be associated with schizophrenia [19]. For the additional subjects, genotypes were determined by TaqMan assay for allelic discrimination using the ABI Prism ${ }^{\circledR} 7000$ Sequence Detection System (Applied Biosystems, Foster City, CA). Schizophrenic and ASD patients were the same as those included in the second step of the mutation screening.

\section{Results}

Expression of the NOS1AP long and short isoforms in the human tissues

In order to study the expression pattern of the NOS1AP long and short isoforms in human tissues, we performed reverse transcriptase - polymerase chain reactions (RT$\mathrm{PCR}$ ) on RNA isolated from different tissues and brains regions (figure 1). Brain samples were obtained from four control individuals. These RT-PCR results are non quantitative and should be taken with care. However, NOS1AP long and short isoforms were not restricted to the brain, but were also detected in testis, prostate, small intestine, blood leukocyte, heart, placenta, lung, kidney and pancreas. In brain, the two isoforms of NOS1AP were also not restricted to a specific brain region (figure 1) and displayed high inter-individual differences.

\section{Mutation screening of NOS1AP in individuals with psychiatric disorders}

All the exons of NOS1AP were directly sequenced in a large subset of subjects $(\mathrm{n}=280)$, including patients with schizophrenia $(\mathrm{n}=72)$, ASD $(\mathrm{n}=81)$ and OCD $(\mathrm{n}=34)$, and in healthy volunteers $(\mathrm{n}=93)$. Only two non-synonymous variations, V37I and D423N were identified (figure 2). V37I was detected in one female patient with OCD. The mutation was also present in her affected brother with OCD and was transmitted by the mother suffering from panic attack (figure 2). We were unable to detect this variation in the extended
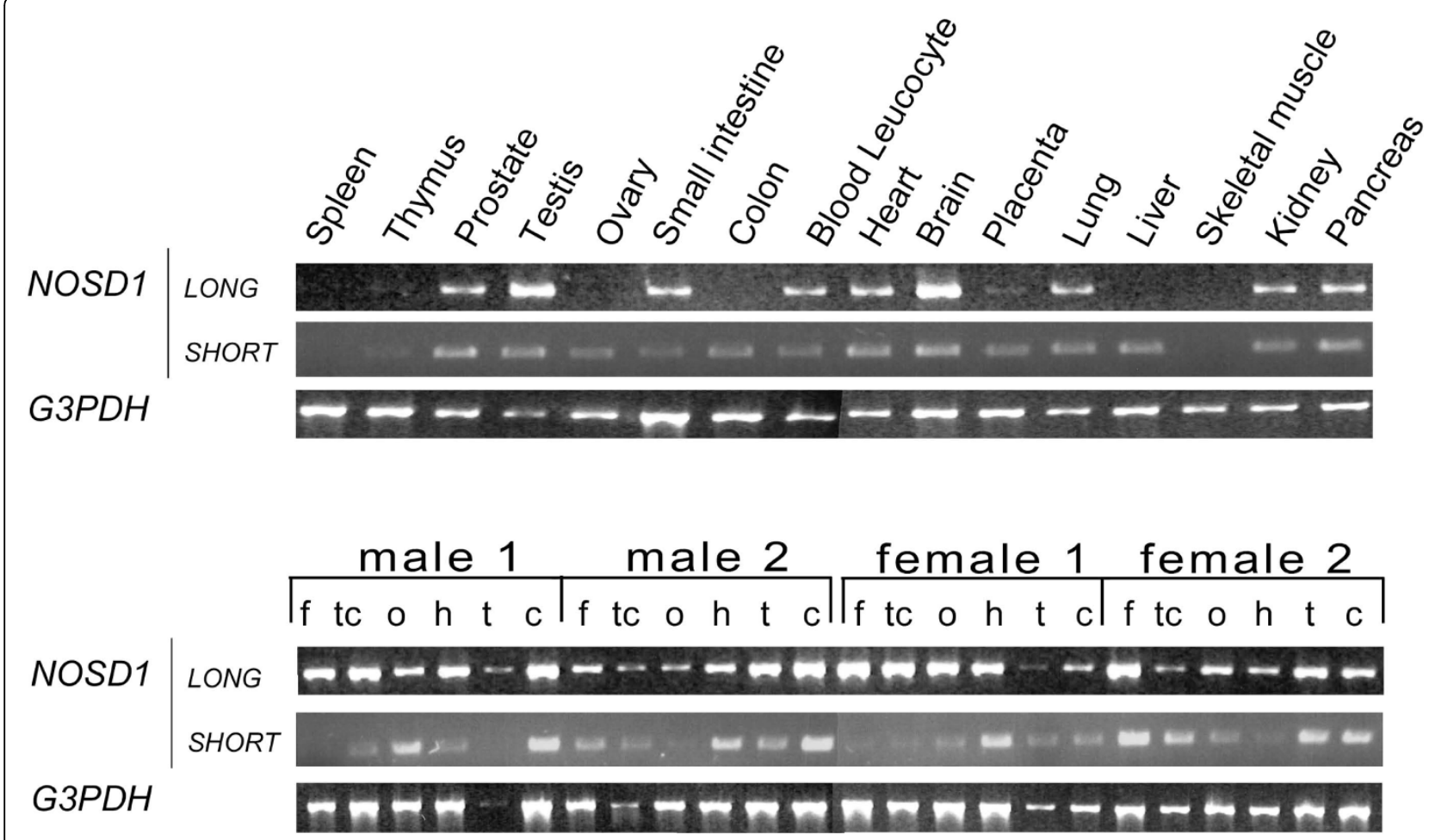

Figure 1 Expression analysis of NOS1AP short and long isoforms in normal control human tissues. One microgram of total RNA from different tissues and specifically from regions of the human brain was reverse transcribed using the Gene Amp RNA PCR kit (Perkin-Elmer Corp., Norwalk, CT) and primers located in exons 1-7, 6-9 and 8-10 (forward -reverse). The ages of the two males and the two females studied were 74, 42,55 , and 36 years-old, with a post-mortem delay of 10, 21, 24, and $2 \mathrm{~h}$, respectively. f: frontal cortex, tc: temporal cortex, o: occipital cortex, h: hippocampus, t: thalamus; c: cerebellum. Normal control human brains were obtained at autopsy under guidelines approved by the ethics committee. 


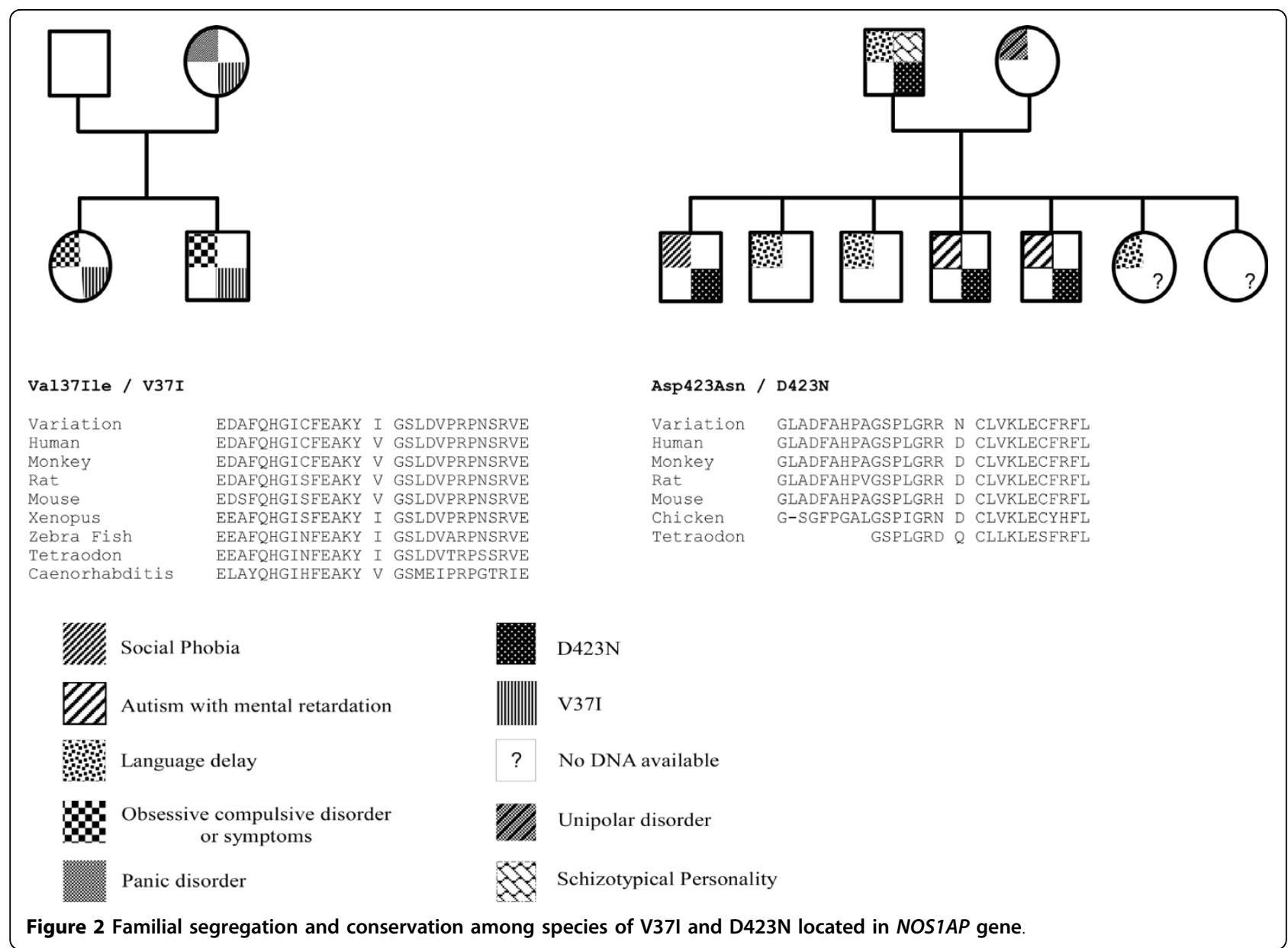

sample of patients with ASD $(\mathrm{n}=224)$ or schizophrenia $(\mathrm{n}=225)$. This rare variant was located in the phosphotyrosin-binding domain that is conserved among mammals, but not in Xenopus and Zebra fish, the latter having a valine to an isoleucine substitution.

The second non-synonymous variation, D423N, was detected in three brothers (figure 2), two affected with ASD and mild mental retardation, and one with social phobia. Two additional brothers with language delay and no autistic symptoms do not carry the mutation. The mutation was transmitted by the father who has a schizotypical personality and a history of language delay during childhood (figure 2). The variation D423N was absent from the extended sample of patients with ASD ( $\mathrm{n}=224)$, schizophrenia $(\mathrm{n}=225)$ and an additional set of 95 controls from North African descent since proband had North African ancestors. D423 is highly conserved among species (figure 2) and is adjacent to the PDZ domain of the short and long isoform of the protein. The variation D423N changes a negatively charged amino acid into a polar uncharged residue. In silico, the variation $\mathrm{D} 423 \mathrm{~N}$ is predicted to alter the protein stability (delta G of -1.16) and function (SIFT program: score $<0.001)$.

\section{Association study in schizophrenic and ASD patients}

In order to test if frequent polymorphisms within NOS1AP were associated with susceptibility to psychiatric disorders, we assessed the frequency of 11 SNPs in patients and controls. Distributions of allelic frequencies of all markers were in Hardy Weinberg Equilibrium in cases and controls ( $p>0.10$ ). The rs347306 and rs347307 located in intron 5 are in strong LD whatever the population considered. Also, rs348624, rs1964052, rs164146 and rs164147 were in the same LD block located in the 3'region of NOS1AP (figure 3 ). We could not detect any significant allelic frequency difference between SCZ and controls or between ASD and controls (table 1). Haplotype analyses defined with confidence intervals did not find any significantly association either (table 2). In order to test the previously observed association between SCZ and SNP rs348624 (R334R) located in exon 9, an additional sample of SCZ $(n=224)$, ASD patients $(n=225)$ and controls $(n=193)$ were genotyped. However, no allelic association was observed. 


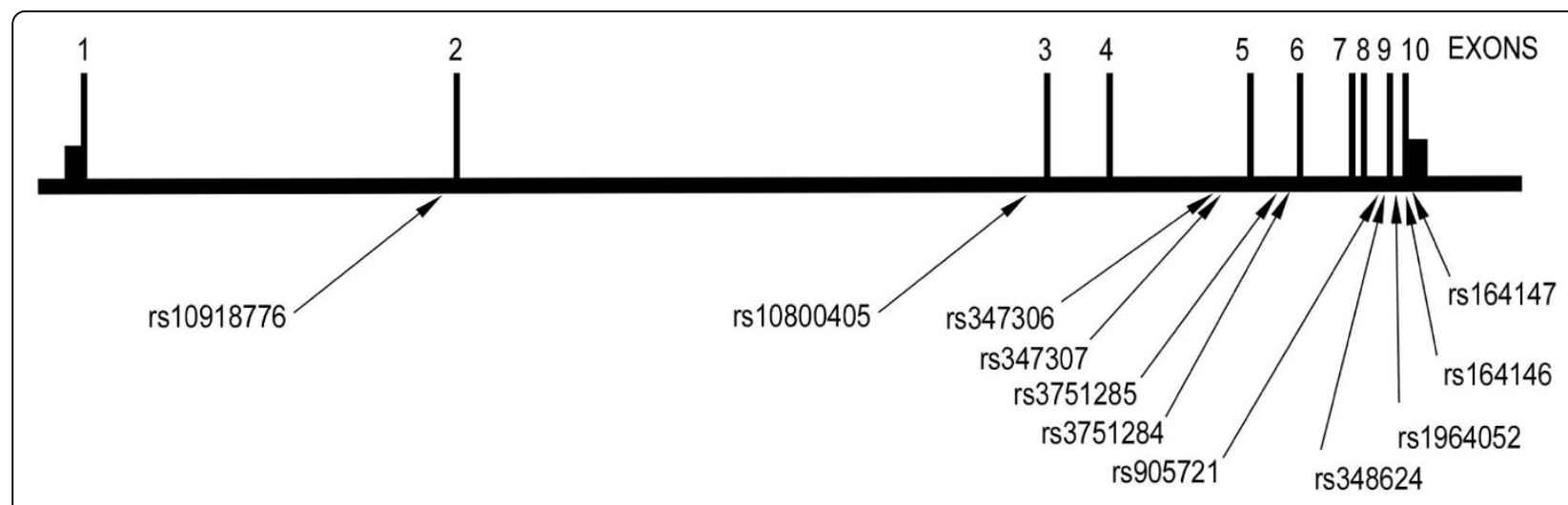

\section{AUTISM SPECTRUM DISORDER ( $\mathrm{n}=81)$}

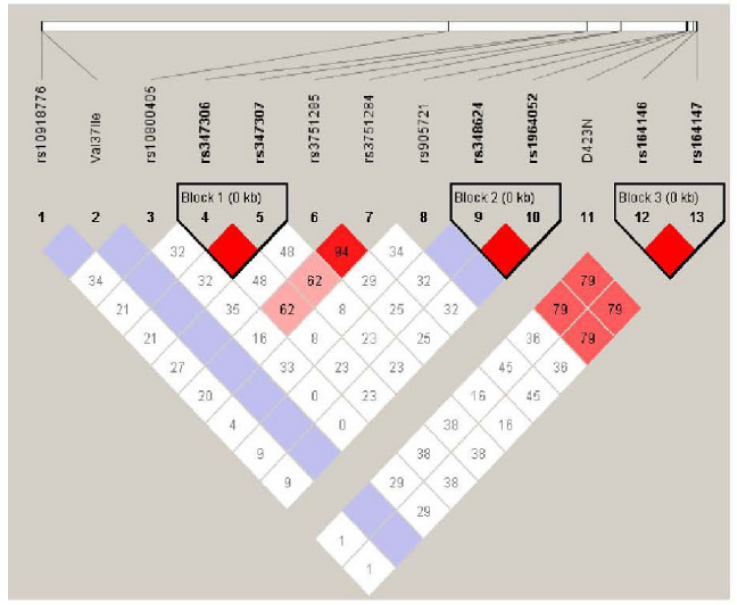

\section{SCHIZOPHRENIA ( $\mathrm{n}=72)$}

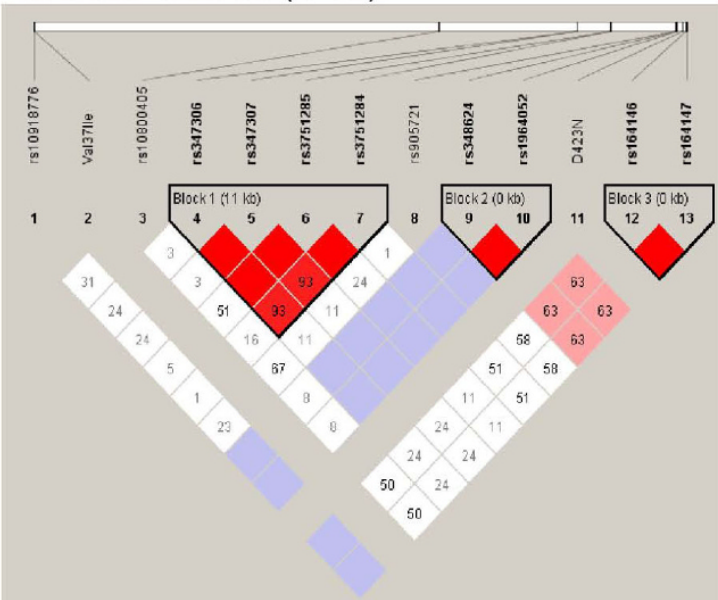

Obsessive Compulsive Disorder $(n=34)$

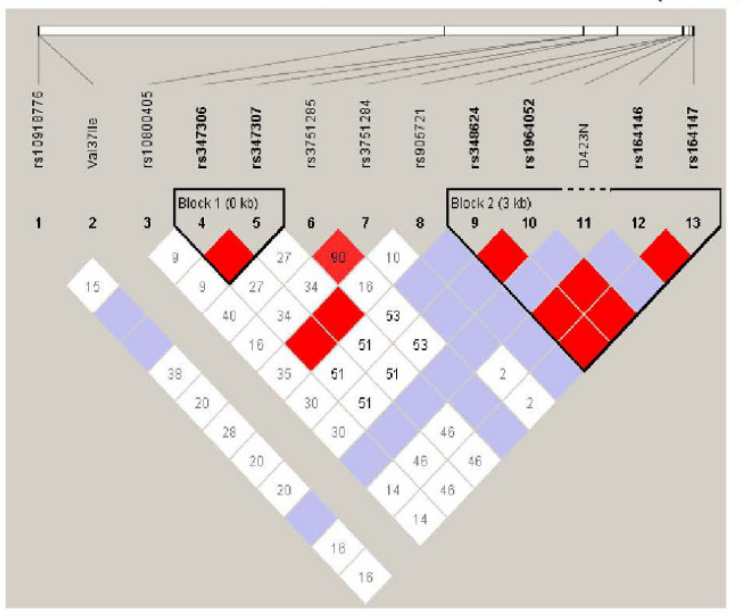

CONTROLS $(n=93)$

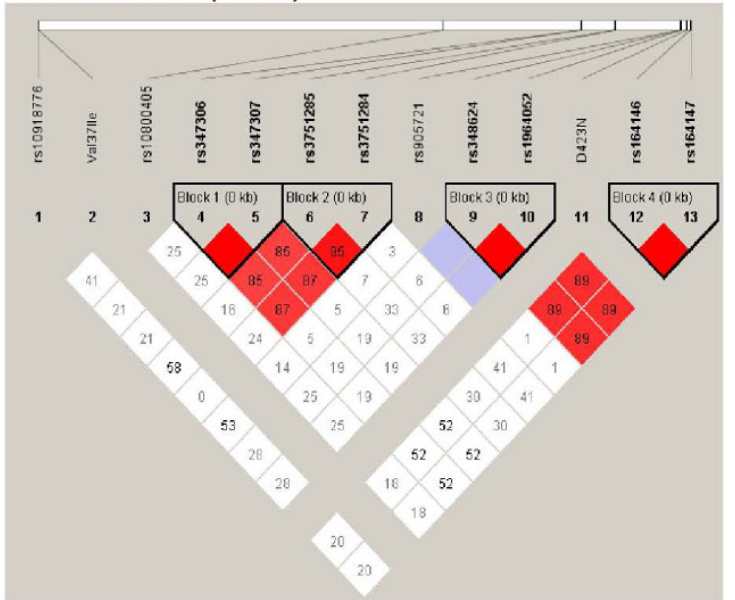

Figure 3 Schematic representation of NOS1AP with location of frequent single nucleotide polymorphisms and Haploview-generated linkage disequilibrium map of the NOS1AP. Region of high $L D\left(D^{\prime}=1\right)$ are shown in bright red. Only ASD, OCD, schizophrenic and control subjets patients are shown in the LD diagram. The numbers in the squares are D prime values $(\times 100)$. 
Table 2 Estimated haplotype frequencies in NOS1AP

\begin{tabular}{|c|c|c|c|c|c|}
\hline \multirow[t]{2}{*}{ Haplotype block } & \multicolumn{3}{|c|}{ Frequency (\%) } & \multicolumn{2}{|l|}{$P$ values } \\
\hline & SCZ & ASD & Control & $\begin{array}{l}\text { SCZ vS. } \\
\text { control }\end{array}$ & $\begin{array}{l}\text { ASD vs. } \\
\text { control }\end{array}$ \\
\hline \multicolumn{6}{|l|}{$\begin{array}{l}1 \text { (rs10918776- } \\
\text { rs10800405) }\end{array}$} \\
\hline $\mathrm{CT}$ & 0.55 & 0.48 & 0.48 & 0.23 & 0.98 \\
\hline $\mathrm{TC}$ & 0.45 & 0.52 & 0.52 & 0.23 & 0.98 \\
\hline \multicolumn{6}{|l|}{$\begin{array}{l}2 \text { (rs3751285 - } \\
\text { rs3751285) }\end{array}$} \\
\hline$A G$ & 0.56 & 0.46 & 0.59 & 0.28 & 0.45 \\
\hline GT & 0.23 & 0.28 & 0.28 & 0.40 & 0.96 \\
\hline AT & 0.11 & 0.17 & 0.13 & 0.74 & 0.33 \\
\hline \multicolumn{6}{|l|}{$\begin{array}{l}3 \text { (rs348624 - } \\
\text { rs1964052) }\end{array}$} \\
\hline CC & 0.89 & 0.85 & 0.91 & 0.50 & $0.07^{*}$ \\
\hline$\pi$ & 0.11 & 0.15 & 0.08 & 0.50 & $0.07^{*}$ \\
\hline \multicolumn{6}{|l|}{$\begin{array}{l}4 \text { (rs164146 - } \\
\text { rs164147) }\end{array}$} \\
\hline GC & 0.83 & 0.84 & 0.84 & 0.71 & 0.99 \\
\hline$C A$ & 0.18 & 0.16 & 0.16 & 0.71 & 0.99 \\
\hline
\end{tabular}

* $P=0.53$ when 10000 permutations where simulated. Significant $P$ values $(<0.05)$ are in bold. Abbreviations: ASD: autism spectrum disorders, SCZ: schizophrenia.

\section{Discussion}

The lack of association between frequent NOS1AP polymorphism and susceptibility to SCZ are in accordance with those obtained in a Caucasian population [30], but contrast with a case control study conducted in a Chinese population, reporting an association between $\mathrm{SCZ}$ and rs348624. These contradictory results could be due to a difference in allelic frequency between populations. Indeed, the major allele frequency for rs348624 in Chinese SCZ patients (0.87) is similar in our patients $(\mathrm{SCZ}$ 0.87; ASD 0.86), but the two control populations differ in allelic frequencies (Chinese controls: 0.82; French controls: 0.89 ). In addition, the association was only suggestive since the same group did not replicate their results when using a family-based approach [31].

The lack of association between frequent SNPs and the disorder does not exclude NOS1AP as a susceptibility gene to psychiatric conditions. Indeed, a larger sample size might detect an association between $\mathrm{SCZ}$ and frequent NOS1AP polymorphism. In addition, private mutations altering the function of NOS1AP may also contribute to the disorder in a subset of patients. Our mutation screening (280 subjects, including patients with SCZ, ASD, OCD, and controls) showed that variations altering the protein sequence of NOS1AP are rare - at least among individuals of European descent. Nevertheless, two changes V37I and D423N were identified in one family with OCD and in one family with ASD, respectively. In public databases three non synonymous variations for NOS1AP, namely: rs41405649, rs4127196, rs34398505 are reported http://www.ncbi.nlm.nih.gov. However, their genotype has not been validated by an independent method and their frequency has not been reported, except for rs34398505 (0.061). The single individual carrying this non synonymous rare variant (NA14649) is a female from African-American ancestor. The variation 37I reported in the OCD family, was present in two affected siblings and in the mother. The mother was directly interviewed, and she suffers from sever panic disorder. In the ASD family, the variation $423 \mathrm{~N}$ segregated with the presence of psychiatric conditions related the broad autism phenotype $[32,33]$. The variant was present in the two affected male siblings, in the brother suffering from a social phobia and transmitted by the father who had a schizotypical personality. The two unaffected brothers do not carry the mutation and have no autistic symptoms. If NOS1AP plays a role in the susceptibility to ASD, it may represent only one of the contributing factors required for the full phenotypic trait of ASD. The conservation of $37 \mathrm{I}$ and $423 \mathrm{~N}$ observed among species suggests that substitution could influence protein function. The mutation V37I only concerns the long NOS1AP isoform, whereas D423N is present in both the short and the long isoform of NOS1AP. Specifically, D423N mutation seems to decrease the protein stability as predicted by the Prediction of Protein Stability Changes upon Mutations Program http://www.ics.uci. edu/ baldig/mutation.html with a delta G of -1.16 . Also, similar results were obtained using the SIFT program. The $\mathrm{D}$ to $\mathrm{N}$ substitution in position 423 is predicted to affect protein function http://sift.jcvi.org/ with a score under 0.001 . At this stage, we lack information on the specific impact of these variants on NOS1AP function to decipher whether these mutations contribute or not to the disorder. Thus, the functional analyses of NOS1AP variants as well as the identification of the genetic/environmental factors, that modulate the expression of NOS1AP in the human brain, are needed to reinforce the potential implication of this gene in the susceptibility to OCD or ASD.

In our four controls individuals, expression of both NOSAP1 isoforms displayed high inter-individual differences whatever the explored brain regions. This interindividual variability in the expression of NOS1AP might contribute to the increased of the short isoform mRNA in the dorso-prefrontal cortex of patients with SCZ [22].

\section{Conclusions}

As reported by Brzustowicz et al., for SCZ [17], variations within the coding sequence of NOS1AP are rare and therefore cannot be considered as susceptibility factors to ASD, OCD and SCZ. However, we cannot exclude that for a very small subset of patients with 
OCD and ASD, NOS1AP may contribute to the disorder. Further genetic and functional studies are warranted to understand the role of NOS1AP in the susceptibility to psychiatric disorders.

\begin{abstract}
Acknowledgements
We thank the patients and their families who made this research possible. We also thank the cell banks of the Cochin hospital (Prof. Delpech) and of the Salpetriere Hospital (Prof. Chelly) and the Centre Investigation Clinique of the Robert Debré hospital (Prof. Jacz-Aigrain) for their medical and technical assistance. This research was supported by the Institut Pasteur, INSERM (National Institute of Health and Medical Research), ANR SynGenASD-LD, Fondation Simone DelDucca, and FondaMental Foundation (Fondation de recherche et de soins en santé mentale).
\end{abstract}

\section{Author details}

'Human Genetics and Cognitive Functions, Institut Pasteur, Paris, France. ${ }^{2}$ INSERM U995, Institut Mondor de Recherche Biomedicale, Psychiatric Genetics, Créteil, France. ${ }^{3}$ APHP, Hôpital Robert Debré, Child and Adolescent Psychiatry, Paris, France. ${ }^{4}$ Department of Child and Adolescent Psychiatry, Göteborg University, Göteborg, Sweden. ${ }^{5}$ APHP, Groupe Hospitalier Henri Mondor - Albert Chenevier, Department of Psychiatry, Créteil, France. ${ }^{6}$ Saint George's Hospital Medical School, London, UK. 'Université Denis Diderot Paris 7, Paris, France. ${ }^{8}$ INSERM, U952, Paris, France. ${ }^{9}$ UPMC Univ Paris 06, Paris, France.

\section{Authors' contributions}

RD carried out molecular genetic studies for all the families, and drafted the manuscript. CB contributed to the collection of clinical data and DNA samples. IS, HA, PC, FS, GN, EH and MR identified and diagnosed the patients. MCM helped to collect the data. TB designed the study and revised the manuscript. ML and CG were principal investigators. All authors read and approved the final manuscript.

\section{Competing interests}

The authors declare that they have no competing interests.

Received: 3 August 2009 Accepted: 5 July 2010 Published: 5 July 2010

\section{References}

1. Brzustowicz LM, Hodgkinson KA, Chow EW, Honer WG, Bassett AS: Location of a major susceptibility locus for familial schizophrenia on chromosome 1q21-q22. Science (New York, NY 2000, 288(5466):678-682.

2. Cai G, Wu X, Li T, Collier DA, Liu X, Feng B, Deng H, Tong D, Li J, Ou J: Linkage analysis of susceptibility genes for familial schizophrenia on chromosome 1 in Chinese population. Zhonghua yi xue yi chuan xue za zhi $=$ Zhonghua yixue yichuanxue zazhi $=$ Chinese journal of medical genetics 2002, 19(6):491-494.

3. Ekelund J, Hovatta I, Parker A, Paunio T, Varilo T, Martin R, Suhonen J, Ellonen $\mathrm{P}$, Chan G, Sinsheimer JS, et al: Chromosome 1 loci in Finnish schizophrenia families. Human molecular genetics 2001, 10(15):1611-1617.

4. Gurling HM, Kalsi G, Brynjolfson J, Sigmundsson T, Sherrington R, Mankoo BS, Read T, Murphy P, Blaveri E, McQuillin A, et al: Genomewide genetic linkage analysis confirms the presence of susceptibility loci for schizophrenia, on chromosomes 1q32.2, 5q33.2, and 8p21-22 and provides support for linkage to schizophrenia, on chromosomes 11q23.3-24 and 20q12.1-11.23. American journal of human genetics 2001, 68(3):661-673.

5. Hovatta I, Varilo T, Suvisaari J, Terwilliger JD, Ollikainen V, Arajarvi R, Juvonen $\mathrm{H}$, Kokko-Sahin ML, Vaisanen L, Mannila $\mathrm{H}$, et al: A genomewide screen for schizophrenia genes in an isolated Finnish subpopulation, suggesting multiple susceptibility loci. American journal of human genetics 1999, 65(4):1114-1124.

6. Hwu HG, Liu CM, Fann CS, Ou-Yang WC, Lee SF: Linkage of schizophrenia with chromosome 1q loci in Taiwanese families. Molecular psychiatry 2003, 8(4):445-452.

7. Buxbaum JD, Silverman J, Keddache M, Smith CJ, Hollander E, Ramoz N, Reichert JG: Linkage analysis for autism in a subset families with obsessive-compulsive behaviors: evidence for an autism susceptibility gene on chromosome 1 and further support for susceptibility genes on chromosome 6 and 19. Molecular psychiatry 2004, 9(2):144-150.

8. Ylisaukko-oja T, Nieminen-von Wendt T, Kempas E, Sarenius S, Varilo T, von Wendt $L$, Peltonen L, Jarvela I: Genome-wide scan for loci of Asperger syndrome. Molecular psychiatry 2004, 9(2):161-168.

9. Russell AJ, Mataix-Cols D, Anson M, Murphy DG: Obsessions and compulsions in Asperger syndrome and high-functioning autism. $\mathrm{Br} J$ Psychiatry 2005, 186:525-528.

10. Shugart YY, Samuels J, Willour VL, Grados MA, Greenberg BD, Knowles JA, McCracken JT, Rauch SL, Murphy DL, Wang Y, et al: Genomewide linkage scan for obsessive-compulsive disorder: evidence for susceptibility loci on chromosomes 3q, 7p, 1q, 15q, and 6q. Molecular psychiatry 2006, 11(8):763-770

11. Chen X, Dunham C, Kendler S, Wang X, O'Neill FA, Walsh D, Kendler KS: Regulator of G-protein signaling 4 (RGS4) gene is associated with schizophrenia in Irish high density families. Am J Med Genet $B$ Neuropsychiatr Genet 2004, 129B(1):23-26.

12. Chowdari KV, Mirnics K, Semwal P, Wood J, Lawrence E, Bhatia T, Deshpande SN, B KT, Ferrell RE, Middleton FA, et al: Association and linkage analyses of RGS4 polymorphisms in schizophrenia. Human molecular genetics 2002, 11(12):1373-1380.

13. Morris DW, Rodgers A, McGhee KA, Schwaiger S, Scully P, Quinn J, Meagher D, Waddington $J$, Gill M, Corvin AP: Confirming RGS4 as a susceptibility gene for schizophrenia. Am J Med Genet B Neuropsychiatr Genet 2004, 125B(1):50-53.

14. Williams NM, Preece A, Spurlock G, Norton N, Williams HJ, McCreadie RG, Buckland P, Sharkey V, Chowdari KV, Zammit S, et al: Support for RGS4 as a susceptibility gene for schizophrenia. Biological psychiatry 2004, 55(2):192-195

15. He G, Liu X, Qin W, Chen Q, Wang X, Yang Y, Zhou J, Xu Y, Gu N, Feng G, et al: MPZL1/PZR, a novel candidate predisposing schizophrenia in Han Chinese. Molecular psychiatry 2006, 11(8):748-751.

16. Puri V, McQuillin A, Choudhury K, Datta S, Pimm J, Thirumalai S, Krasucki R, Lawrence J, Quested D, Bass N, et al: Fine mapping by genetic association implicates the chromosome 1q23.3 gene UHMK1, encoding a serine/ threonine protein kinase, as a novel schizophrenia susceptibility gene. Biological psychiatry 2007, 61(7):873-879.

17. Brzustowicz LM, Simone J, Mohseni P, Hayter JE, Hodgkinson KA, Chow EW, Bassett AS: Linkage disequilibrium mapping of schizophrenia susceptibility to the CAPON region of chromosome 1q22. American journal of human genetics 2004, 74(5):1057-1063.

18. Miranda A, Garcia J, Lopez C, Gordon D, Palacio C, Restrepo G, Ortiz J, Montoya G, Cardeno C, Calle J, et al: Putative association of the carboxyterminal PDZ ligand of neuronal nitric oxide synthase gene (CAPON) with schizophrenia in a Colombian population. Schizophrenia research 2006, 82(2-3):283-285.

19. Zheng Y, Li H, Qin W, Chen W, Duan Y, Xiao Y, Li C, Zhang J, Li X, Feng G, et al: Association of the carboxyl-terminal PDZ ligand of neuronal nitric oxide synthase gene with schizophrenia in the Chinese Han population. Biochemical and biophysical research communications 2005, 328(4):809-815.

20. Kremeyer B, Garcia J, Kymalainen H, Wratten N, Restrepo G, Palacio C, Miranda AL, Lopez C, Restrepo M, Bedoya G, et al: Evidence for a role of the NOS1AP (CAPON) gene in schizophrenia and its clinical dimensions: an association study in a South American population isolate. Hum Hered 2009, 67(3):163-173.

21. Cheah JH, Kim SF, Hester LD, Clancy KW, Patterson SE, Papadopoulos V, Snyder SH: NMDA receptor-nitric oxide transmission mediates neuronal iron homeostasis via the GTPase Dexras1. Neuron 2006, 51(4):431-440.

22. Xu B, Wratten N, Charych El, Buyske S, Firestein BL, Brzustowicz LM: Increased expression in dorsolateral prefrontal cortex of CAPON in schizophrenia and bipolar disorder. PLoS medicine 2005, 2(10):e263.

23. Eastwood SL: Does the CAPON gene confer susceptibility to schizophrenia? PLoS medicine 2005, 2(10):e348.

24. Wratten NS, Memoli H, Huang Y, Dulencin AM, Matteson PG, Cornacchia MA, Azaro MA, Messenger J, Hayter JE, Bassett AS, et al: Identification of a schizophrenia-associated functional noncoding variant in NOS1AP. Am J Psychiatry 2009, 166(4):434-441.

25. Nurnberger JI Jr, Blehar MC, Kaufmann CA, York-Cooler C, Simpson SG, Harkavy-Friedman J, Severe JB, Malaspina D, Reich T: Diagnostic interview for genetic studies. Rationale, unique features, and training. NIMH 
Genetics Initiative. Archives of general psychiatry 1994, 51(11):849-859, discussion 863-844.

26. Orvaschel H, Puig-Antich J, Chambers W, Tabrizi MA, Johnson R: Retrospective assessment of prepubertal major depression with the Kiddie-SADS-e. Journal of the American Academy of Child Psychiatry 1982, 21(4):392-397.

27. Lord C, Rutter M, Le Couteur A: Autism Diagnostic Interview-Revised: a revised version of a diagnostic interview for caregivers of individuals with possible pervasive developmental disorders. Journal of autism and developmental disorders 1994, 24(5):659-685.

28. Maxwell M: Family Interview for Genetics Study (FIGS): A Manual for FIGS. Clinical Neurogenetics Branch, Intramural Research Program, Bethesda: National Institute of Mental Health 1992.

29. Gabriel SB, Schaffner SF, Nguyen H, Moore JM, Roy J, Blumenstiel B, Higgins J, DeFelice M, Lochner A, Faggart M, et al: The structure of haplotype blocks in the human genome. Science (New York, NY) 2002, 296(5576):2225-2229.

30. Puri V, McQuillin A, Thirumalai S, Lawrence J, Krasucki R, Choudhury K, Datta S, Kerwin S, Quested D, Bass N, et al: Failure to confirm allelic association between markers at the CAPON gene locus and schizophrenia in a British sample. Biological psychiatry 2006, 59(2):195-197.

31. Fang C, Tang $W$, Tang RQ, Wang L, Zhou GQ, Huang K, Li XW, Feng GY, He M, Du LZ, et al: Family-based association studies of CAPON and schizophrenia in the Chinese Han population. Progress in neuropsychopharmacology \& biological psychiatry 2008, 32(5):1210-1213.

32. Burbach JP, van der Zwaag B: Contact in the genetics of autism and schizophrenia. Trends in neurosciences 2009, 32(2):69-72.

33. Dawson G, Webb S, Schellenberg GD, Dager S, Friedman S, Aylward E, Richards T: Defining the broader phenotype of autism: genetic, brain, and behavioral perspectives. Development and psychopathology 2002, 14(3):581-611.

\section{Pre-publication history}

The pre-publication history for this paper can be accessed here: http://www.biomedcentral.com/1471-2350/11/108/prepub

\section{doi:10.1186/1471-2350-11-108}

Cite this article as: Delorme et al:: Mutation screening of NOS1AP gene

in a large sample of psychiatric patients and controls. BMC Medical

Genetics 2010 11:108.

\section{Submit your next manuscript to BioMed Central and take full advantage of:}

- Convenient online submission

- Thorough peer review

- No space constraints or color figure charges

- Immediate publication on acceptance

- Inclusion in PubMed, CAS, Scopus and Google Scholar

- Research which is freely available for redistribution 